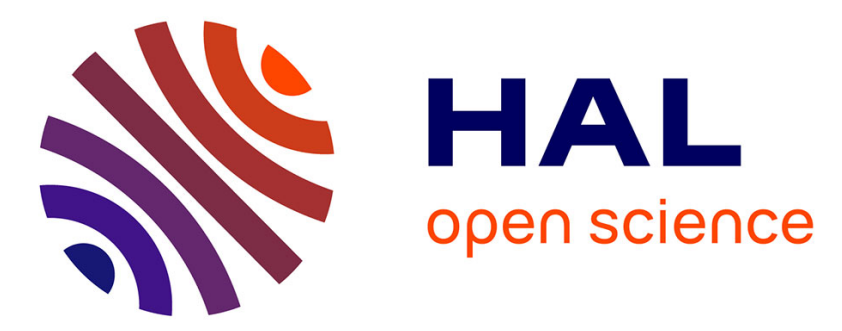

\title{
Enhanced Passive and Active Processing of Syllables in Musician Children
}

\author{
Julie Chobert, Céline Marie, Clément François, Daniele Schön, Mireille R \\ Besson
}

\section{- To cite this version:}

Julie Chobert, Céline Marie, Clément François, Daniele Schön, Mireille R Besson. Enhanced Passive and Active Processing of Syllables in Musician Children. Journal of Cognitive Neuroscience, 2011, 10, pp.420 - 3887. 10.1162/jocn_a_00088. hal-01382742

\section{HAL Id: hal-01382742 \\ https://hal-amu.archives-ouvertes.fr/hal-01382742}

Submitted on 17 Oct 2016

HAL is a multi-disciplinary open access archive for the deposit and dissemination of scientific research documents, whether they are published or not. The documents may come from teaching and research institutions in France or abroad, or from public or private research centers.
L'archive ouverte pluridisciplinaire HAL, est destinée au dépôt et à la diffusion de documents scientifiques de niveau recherche, publiés ou non, émanant des établissements d'enseignement et de recherche français ou étrangers, des laboratoires publics ou privés. 


\title{
Enhanced Passive and Active Processing of Syllables in Musician Children
}

\author{
Julie Chobert $^{1}$, Céline Marie ${ }^{2}$, Clément François ${ }^{1}$, \\ Daniele Schön $^{1}$, and Mireille Besson ${ }^{1}$
}

\begin{abstract}
The aim of this study was to examine the influence of musical expertise in 9-year-old children on passive (as reflected by MMN) and active (as reflected by discrimination accuracy) processing of speech sounds. Musician and nonmusician children were presented with a sequence of syllables that included standards and deviants in vowel frequency, vowel duration, and VOT. Both the passive and the active processing of duration and VOT deviants
\end{abstract}

\section{INTRODUCTION}

Results of many experiments in the neuroscience of music have demonstrated an advantage of musician over nonmusician adults for passive and active processing of harmonic and musical sounds. Passive (preattentive) auditory processing has generally been examined using both the MMN (Näätänen, Gaillard, \& Mäntysalo, 1978) and the auditory brainstem-evoked responses (BERs; Jewett, Romano, \& Williston, 1970). Results typically showed larger and shorter MMNs to deviants in pure tones, harmonic tones, and musical sounds in musicians than in nonmusicians (e.g., Nikjeh, Lister, \& Frisch, 2009; Tervaniemi, Rytkönen, Schröger, Ilmoniemi, \& Näätänen, 2001). Moreover, the BERs to musical sounds are also more robust in musicians than in nonmusicians (see Kraus \& Chandrasekaran, 2010, for a review). Active auditory processing has been examined by recording both behavioral measures (percent errors and RTs) and brain ERPs when participants are asked to focus attention on the sounds. Results showed that musical expertise decreases the frequency discrimination thresholds of pure and harmonic tones (Kishon-Rabin, Amir, Vexler, \& Zaltz, 2001; Spiegel \& Watson, 1984) and increases pitch and duration discrimination accuracy (Marie, Kujala, \& Besson, in press; Tervaniemi, Just, Koelsch, Widmann, \& Schröger, 2005) when participants have to press a response button as fast as possible on hearing a deviant in a sound sequence. Moreover, by using more ecological musical contexts, other results revealed that musicians recognize familiar melodies and detect subtle variations of pitch faster and more accurately than nonmusicians (e.g., Schön, Magne,

\footnotetext{
${ }^{1}$ CNRS \& Université de la Méditerranée, Marseille, France,
}

${ }^{2}$ McMaster University, Hamilton, Canada were enhanced in musician compared with nonmusician children. Moreover, although no effect was found on the passive processing of frequency, active frequency discrimination was enhanced in musician children. These findings are discussed in terms of common processing of acoustic features in music and speech and of positive transfer of training from music to the more abstract phonological representations of speech units (syllables).

\& Besson, 2004; Besson \& Faïta, 1995). These differences at the behavioral level were most often associated with larger amplitude and/or shorter latency of ERP components such as the $\mathrm{N} 2$ and $\mathrm{P} 3$ components.

More surprisingly, recent evidence also suggests that the advantage because of musical training in processing musical sounds extends to speech sounds. Both the BERs and MMNs to speech or speech-like stimuli have been shown to occur earlier and/or to be larger in musicians than in nonmusicians (Bidelman, Gandour, \& Krishnan, 2011; Chandrasekaran, Krishnan, \& Gandour, 2009; Musacchia, Strait, \& Kraus, 2008; Musacchia, Sams, Skoe, \& Kraus, 2007; Wong, Skoe, Russo, Dees, \& Kraus, 2007). For instance, Chandrasekaran et al. (2009) showed that deviants in pitch contour homologous to Mandarin tones elicited larger MMNs in English musicians than in English nonmusicians. They interpreted this result as reflecting an increased ability of musicians to process pitch variations not only in music but also in speech.

When participants are asked to focus attention on the sounds, Reinke, He, Wang, and Alain (2003) reported increased P2 amplitude with musical training in a vowel discrimination task on the basis of pitch. Using natural speech, Besson and colleagues have further demonstrated that musicians detected subtle pitch manipulations on sentence final words better than nonmusicians; this effect was associated with increased amplitude and shorter latency of the P300 or late positivity component (Marques, Moreno, Castro, \& Besson, 2007; Schön et al., 2004). Moreover, Marie, Magne, and Besson (2011) have recently shown that musical expertise also facilitates the processing of the temporal structure of syllables and of the metric structure of words. Taken together, these results demonstrate that longterm musical training not only facilitates the processing of 
unattended and attended harmonic and musical sounds but also impacts on the processing of speech sounds. This finding has been taken as evidence that some aspects of music and speech involve common processing mechanisms and transfer effects. However, all these experiments have been conducted in adults. The aim of the present study was, therefore, to determine whether musical expertise also facilitates passive and active processing of speech sounds in children.

Similar to adults, previous results have demonstrated that, when children are asked to focus attention on sounds, the processing of harmonic and musical sounds is enhanced in children with 2-4 years of musical training (that is, in children on their way toward musicianship, referred to as musician children in the remainder of this article) compared with children with no music training (referred to below as nonmusicians; Magne, Schön, \& Besson, 2006; Koelsch, Fritz, Schulze, Alsop, \& Schlaug, 2005; Schlaug, Norton, Overy, \& Winner, 2005; Shahin, Roberts, \& Trainor, 2004; Trainor, Shahin, \& Roberts, 2003). For instance, Trainor et al. (2003) found larger P2-evoked responses to pure violin and piano tones in 4- to 5-year-old musician compared with nonmusician children, thereby showing that the effects of musical training on cortical representations are present early in development. Using fMRI, Koelsch et al. (2005) have found larger activations in frontal and temporal regions in musician compared with nonmusician children when they were asked to decide whether musical sequences were syntactically regular or not. These differences of activation between musicians and nonmusicians were taken to reflect more specific representations of musical regularities in musician children. Recently, Hyde et al. (2009) were able to demonstrate that 15 months of musical training in 6-year-old children induced structural changes in several brain regions (primary motor and right auditory cortex and the corpus callosum) known to be of critical importance for instrumental music performance and auditory processing in adults (e.g., Loui, Alsop, \& Schlaug, 2009; Schlaug et al., 2005; Gaser \& Schlaug, 2003; Schneider et al., 2002). Importantly, these structural changes were positively correlated with the level of performance in four-finger motor sequencing tasks and in melodic and rhythmic discrimination tests.

Nonetheless, very few experiments have addressed the issue of whether musical expertise influences speech processing in children. In one such study, Magne et al. (2006) demonstrated enhanced pitch processing of sentence final words in 8-year-old musician (with 4 years of musical practice) compared with nonmusician children when they were asked to focus attention on final words to decide whether their pronunciation was normal or strange. These results were later reproduced by Moreno et al. (2009), who used a longitudinal approach, again with 8-year-old nonmusician children. After 6 months of training, children who received music training not only showed enhanced pitch processing in music but also in speech compared with children who received painting training. These results were important in showing that the effects previously found with musician children (Magne et al., 2006) did not only result from specific predispositions for music but were a direct result of music training.

Moreno et al. (2009) also found that musical training facilitated the reading of phonologically complex words, which is in line with previous evidence indicating that musical aptitude is positively correlated with phonological abilities (e.g., Slevc \& Miyake, 2006; Overy, Nicolson, Fawcett, \& Clarke, 2003; Anvari, Trainor, Woodside, \& Levy, 2002). For instance, Anvari et al. (2002) showed that musical aptitude in 4- to 5-year-old children was significantly correlated with both phonological awareness and reading development. Moreover, Milovanov et al. (2009) reported enhanced MMNs to speech duration deviants in 10- to 12-year-old children with high musical aptitudes and pronunciation skills compared with children who lacked these skills. Thus, musical expertise, musical training, and musical aptitudes all seem to impact on several aspects of speech processing and on reading in children. Note that we use "musical expertise" to refer to the comparison between children trained with music for several years and nonmusician children who have not received musical training apart from compulsory school education (e.g., Magne et al., 2006). By contrast, we use "musical training" to refer to research programs in which nonmusician children are trained with music for the experiment (e.g., Moreno et al., 2009) and "musical aptitudes" when nonmusician children are not trained with music but are tested on their musical abilities (e.g., Milovanov et al., 2009).

However, to our knowledge, no study has yet been conducted to determine whether musical expertise also influences the preattentive processing of speech sounds in children. The only related study was conducted by Milovanov et al. (2009), but as mentioned above, they examined the effects of musical aptitudes rather than the effects of musical expertise. In the present experiment, we compared musician children with an average of 4 years of musical training with nonmusician children. We used the multifeature MMN design (Näätänen, Pakarinen, Rinne, \& Takegata, 2004), in which standard sounds are presented together with several types of deviants that differ from the standard in one specific feature. ${ }^{1}$ The multifeature MMN design has already been tested using speech sounds, and results were similar to those obtained with the traditional oddball paradigm both in adults (Pakarinen et al., 2009) and in 6-yearold children (Lovio et al., 2009).

We used the syllable "Ba" as standard as well as deviants on three dimensions: vowel frequency, vowel duration, and VOT. ${ }^{2}$ Moreover, deviants in each dimension were either close to or far from the standard (small and large deviants). After the MMN experiment, during which children were asked to ignore the sounds and to focus attention on a silent movie (passive listening), the same sequence of syllables was presented again, and children were asked to focus attention on the sounds and to press a button each time they heard a deviant (active listening). On the basis of previous results (e.g., Novitski, Tervaniemi, Huotilainen, \& 
Näätänen, 2004; Tiitinen, May, Reinikainen, \& Näätänen, 1994; Sams, Paavilainen, Alho, \& Näätänen, 1985), we expected to find larger MMN amplitude during passive listening and higher accuracy in the active discrimination task to large than to small deviants. Related to the three types of deviants used in the experiment, we present specific hypotheses on the basis of the literature reviewed above.

For frequency deviants, previous results have clearly demonstrated enhanced active processing of pitch at the word level in both musician adults (Musacchia et al., 2007, 2008; Marques et al., 2007; Schön et al., 2004) and children (Moreno et al., 2009; Magne et al., 2006). Thus, we expected this processing advantage at the word level to extend to the active processing of pitch variations at the syllable level. Moreover, previous results with nonspeech sounds in adults (e.g., Brattico, Näätänen, \& Tervaniemi, 2001; Tervaniemi et al., 2001; Koelsch, Schröger, \& Tervaniemi, 1999) led us to predicted larger MMNs to frequency deviants in musician compared with nonmusician children.

Our hypothesis regarding duration deviants is based on results by Milovanov et al. (2009) showing larger MMNs to speech duration deviants in children with high musical aptitudes; thus, we expected larger MMNs in musician than in nonmusician children. Moreover, although to our knowledge, the active processing of vowel duration has not yet been tested in children, Marie, Magne, et al. (2011) reported an enhanced discrimination of vowel duration in musician compared with nonmusician adults. Therefore, it was of interest to determine whether similar results would be found for children.

Finally and perhaps of most interest are the predictions for phonological deviants that were built by manipulating the VOT. Changes in VOT allow one to perceive stop consonants as voiced (e.g., /b/) or voiceless (e.g., /p/). In French, consonants with VOT values shorter than the phonemic boundary (around $0 \mathrm{msec}$ ) tend to be classified as voiced (negative VOT around $-100 \mathrm{msec}$ ) and consonants with VOT values longer than 0 msec tend to be classified as voiceless (positive VOT around +30 msec; Serniclaes, 1987). VOT perception has been studied using the MMN in adults (e.g., Phillips et al., 2000; Sharma \& Dorman, 1999), and typically, results showed that MMNs were smaller for within-category (e.g., different types of "Ba") than for across-category consonant changes (e.g., from "Ba" to "Pa"), despite the fact that the size of the change in duration was the same in both cases. Thus, an acrosscategory change from 30 to $50 \mathrm{msec}$ VOT in American English elicited an MMN in American English adults, whereas a within-category change from 60 to $80 \mathrm{msec}$ VOT did not (Sharma \& Dorman, 1999).

In the present experiment, the standard "Ba" had a VOT of -91 msec ( $\left.\mathrm{Ba}_{-91 \mathrm{msec}}\right)$ and the VOT deviants were issued from a "Ba"-"Pa" continuum with the small deviant located at middle position $\left(\mathrm{Ba}_{-36} \mathrm{msec}\right)$ and the large deviant at extreme position ( $\left.\mathrm{Ba}_{-8} \mathrm{msec}\right)$, very close to "Pa." As mentioned above, previous results have shown positive correlations between musical ability, phonological aware- ness and reading skills in both adults and children (e.g., Milovanov et al., 2009; Slevc \& Miyake, 2006; Overy et al., 2003; Anvari et al., 2002). On the basis of these results and on those mentioned above, we hypothesized that both musician and nonmusician children should perceive large deviants as across-category changes. Consequently, they should elicit large MMNs and be discriminated with high accuracy by both groups of children. However, the hypotheses for the small deviants are more contrastive. If musical training helps musician children to perceive the subtle difference in VOT between the small deviant $\left(\mathrm{Ba}_{-36 \mathrm{msec}}\right)$ and the standard "Ba-91 msec," small deviants should also elicit an MMN in musicians, although smaller in amplitude than the MMN to Large deviants. Moreover, discrimination accuracy for small deviants should also be higher for musician than for nonmusician children. By contrast, if nonmusician children do not perceive such a small difference in VOT, no MMN should be found for Small deviants.

\section{METHODS}

\section{Participants}

Twenty-eight children participated to 1.25-hr experimental session (including instructions and setup: $0.5 \mathrm{hr}$ head-cap and other electrodes placement, $0.25 \mathrm{hr}$ MMN experiment, and $0.05 \mathrm{hr}$ discrimination experiment including resting periods). Among them, 14 were musicians (mean age $=$ 9.4 years old, $S D=1.4$ years; 12 girls) and 14 were nonmusicians (mean age $=9.0$ years old, $S D=1.6$ years; 8 girls). Musician children had 4 years of musical training on average, and their musical background is detailed in Table 1. Nonmusician children did not receive formal music training

Table 1. Musical Background of the Musician Children

\begin{tabular}{lc}
\hline Instrument & Duration of the Practice (years) \\
\hline Violin & 3 \\
String-bass & 4 \\
Violin & 4 \\
Violin & 4 \\
Violin & 5 \\
Violin & 3 \\
Violin & 3 \\
Violin & 4 \\
Violin & 3 \\
Piano & 6 and 3 \\
Piano and violin & 5 and 4 \\
Oboe and horn & 3 \\
Flute & 3 \\
Cello & $\mathbf{4}(\boldsymbol{D}=\mathbf{1})$ \\
Mean &
\end{tabular}


other than music classes provided at school. In each group, three children were left-handed. All children were native speakers of French and had normal or corrected-to-normal vision, normal audition, and no known neurological deficits as determined from a detailed questionnaire that parents were asked to fill in before the experiment. This questionnaire also revealed that all children had similar socioeconomic backgrounds (the French middle class) as indicated by the profession of the parents and that all children were involved in extracurricular activities (e.g., sports, theater, drawing, etc.). This study was conducted in accordance with local norms and guidelines for the protection of human subjects. All children agreed to participate in the experiment once the procedure had been explained to them. Children were also told that they could ask us to stop the experiment at anytime if they felt uncomfortable (none did). Finally, at least one parent accompanied each child to the laboratory and signed an informed a consent form before the experiment. Children were given presents at the end of the session to thank them for their participation.

\section{Stimuli}

Stimuli were syllables with consonant-vowel structure. The standard stimulus "Ba" had a fundamental frequency (F0) of $106 \mathrm{~Hz}$, a vowel duration of $186 \mathrm{msec}$ and a VOT of -91 msec for a total duration of the stimulus of $277 \mathrm{msec}$. Frequency, duration, and VOT deviants were used with two levels of deviance size (small and large) from the standard stimuli.

For frequency deviants, the vowel duration and the VOT were the same as for the standard but the F0 of the vowel was raised using the Praat software (Boersma \& Weenink, 2001). For large deviants, the F0 was increased to $127 \mathrm{~Hz}$ (i.e., $21 \mathrm{~Hz}$ higher than standard, 20\% of increase) and for small deviants to $112 \mathrm{~Hz}$ (i.e., $6 \mathrm{~Hz}$ higher than standard, $6 \%$ of increase).

For duration deviants, the F0 and the VOT were the same as for the standard, but vowel duration was shortened using the Adobe audition software. For large deviants, vowel duration was $73 \mathrm{msec}$ (i.e., $113 \mathrm{msec}$ shorter than the standard, 61\% of decrease; total duration large deviant $=164 \mathrm{msec}$ ) and for the small deviant $139 \mathrm{msec}$ (i.e., 47 msec shorter than the standard, 25\% of decrease; total duration small deviant $=230 \mathrm{msec}$ ).

For VOT deviants, the F0 and vowel duration were the same as for the standard stimuli but the VOT changed. Small and large deviants were selected on a "Ba-Pa" continuum that comprised nine sounds. The large deviant was "Ba-8 msec" (VOT $=-8$ msec; i.e., 83 msec shorter than the standard, 91\% of decrease) and the small deviant was "Ba-36 msec" (VOT $=-36$ msec; i.e., 55 msec shorter than the standard, $60 \%$ of decrease).

\section{Procedure}

Children sat in a comfortable chair in a Faraday shielded room, 1-m distance from a computer screen. The session comprised two experiments. In the passive listening experiment, the EEG was recorded while children watched a silent subtitled movie displayed on the computer screen. They were told to watch the movie without paying attention to the sounds that were presented through headphones. Frequency, duration, and VOT deviants, each with two levels of deviance size (small and large from the standard), were randomly presented within the auditory sequence with a fixed SOA of 600 msec synchronized with vowel onset. A total of 1200 stimuli were used with 432 deviants ( 72 for each of the six deviant types; $6 \%$ probability). All stimuli were presented within a single block that lasted for $12.2 \mathrm{~min}$. To avoid any carryover effects of attention (e.g., see Näätänen, Schröger, Karakas, Tervaniemi, \& Paavilainen, 1993), the passive condition always preceded the active condition. In the active listening experiment, children were asked to focus attention on the sounds and to press a response button as fast and as accurately as possible each time they heard a deviant. They were first familiarized with the standard and deviant sounds in a training session. Immediately after training, they performed the experiment. On the basis of the results of a pilot experiment showing that 600 msec SOA was too fast to allow children enough time to give their response, the SOA was increased to $1000 \mathrm{msec}$. A total of 666 stimuli were randomly presented within the auditory sequence with 180 deviants (30 for each of the six deviant types; $4.5 \%$ probability to increase the time interval between deviants and consequently between button press) of 486 standards. As the task remained very demanding for the children, the stimulus sequence was split into three blocks of 4 min each, separated by resting periods. The EEG was not analyzed in the active condition because trials were contaminated by too many artifacts (mainly blinks and motor activity).

\section{ERPs Recording and Processing}

The EEG was continuously recorded at a sampling rate of $512 \mathrm{~Hz}$ using a Biosemi amplifier system (Amsterdam, BioSemi Active 2) from 32 active $\mathrm{Ag}-\mathrm{AgCl}$ electrodes mounted on a child-sized elastic cap (Biosemi Pintype) at standard positions of the International 10/20 System (Jasper, 1958): Fz, Cz, Pz, Oz, Fp1, Fp2, AF3, AF4, F7, F8, F3, F4, Fc5, Fc6, Fc1, Fc2, T7, T8, C3, C4, Cp5, Cp6, Cp1, Cp2, P3, P4, PO3, PO4, P7, P8, O1, O2). Data were rereferenced off-line to the algebraic average of the left and right mastoids (or to the nose recordings) and filtered with a bandpass of $1-30 \mathrm{~Hz}$ (12 dB/oct). Moreover, to detect horizontal eye movements and blinks, the EOG was recorded from flat-type active electrodes placed $1 \mathrm{~cm}$ to the left and right of the external canthi and from an electrode beneath the right eye. Three additional electrodes were placed on the left and right mastoids and on the nose. EEG data were analyzed using the Brain Vision Analyzer Software (Version 01/04/2002; Brain Products, Gmbh, München, Germany). Recordings were segmented into 700-msec epochs (from -100 to $600 \mathrm{msec}$ post- 
stimulus onset). Epochs with electric activity exceeding baseline activity by $75 \mu \mathrm{V}$ were considered as artifacts and were automatically rejected from further processing $($ mean $=6 \%)$.

\section{MMNs Data Analysis}

ERPs data were analyzed using the mastoid off-line referenced data and averaged for each child and for each experimental condition. Difference waveforms were obtained by subtracting ERPs elicited by the standards from those elicited by each deviant type. The MMN was also computed by using the nose reference to verify the typical MMN inversion between Fz/Cz and the mastoids electrodes (see Näätänen, Paavilainen, Rinne, \& Alho, 2007). However, because mastoid-referenced averages typically show a better signalto-noise ratio than the nose-referenced averages (Kujala, Tervaniemi, \& Schröger, 2007; Schröger \& Wolff, 1998), the former were used to quantify MMN amplitude. To this aim, the MMN was first identified at Fz as the most negative peak in the grand average difference waveform in each condition and a 50-msec window was chosen, centered on the peak of the MMN to each deviant. Mean amplitudes were then measured within this latency window for each participant and for each deviant. Maximum MMN amplitude developed between 300 and $400 \mathrm{msec}$ for frequency deviants, between 200 and $400 \mathrm{msec}$ for duration deviants and between 50 and $150 \mathrm{msec}$ for VOT deviants. Moreover, the latency of the most negative peak at Fz was also measured for each subject. Finally, the P3a was identified in the grand average at $\mathrm{Cz}$ between 200 and 400 msec postdeviant onset. Mean amplitudes were then computed at each electrode for each deviant and for each participant in a 50-msec window centered at the peak.

Five-way repeated measures ANOVAs were first conducted on MMN and P3 amplitudes that included Group (musicians and nonmusicians) as a between-subject factor and Dimension (frequency, duration, and VOT), Deviance Size (small and large), Laterality (left: F3, C3, P3; midlines: Fz, Cz, Pz; and right: F4, C4, P4), and Anterior-Posterior Locus (frontal, central, and parietal) as within-subject factors. Moreover, three-way repeated measures ANOVAs were also conducted on MMN latency at Fz that included Group (musicians vs. nonmusicians) as a between-subject factor, and Dimension (frequency, duration, and VOT) and Deviance size (small and large) as within-subject factors. If the Group $\times$ Dimension interaction was significant, fourway ANOVAs (or two-way ANOVAs for latency) were conducted for each dimension separately (by including Group as a between-subject factor and Deviance Size, Laterality, and Anterior-Posterior Locus as within-subject factors for amplitude measures, and Group and Deviance size for latency measures). Greenhouse-Geisser corrections were applied when appropriate and Tukey post hoc tests were conducted to determine the source of significant interactions.

\section{Behavioral Data Analysis in the Active Discrimination Task}

Responses between 300 and 1200 msec from deviant onset were considered as correct detections. On the basis of children's average RTs and on the duration of the SOA (1000 msec), responses shorter than $300 \mathrm{msec}$ were considered as anticipations and responses longer than $1200 \mathrm{msec}$ as omissions and both were excluded from further analyses. ${ }^{3}$ Mean percentage of errors (\%err) and RTs were computed for the six deviant types. A three-way repeated measures ANOVA including Group (musicians and nonmusicians) as a between-subject factor, and Dimension (frequency, duration, and VOT) and Deviance Size (small and large) as within-subject factors was conducted for both \%err and RTs.

\section{RESULTS \\ Passive Discrimination: MMN Amplitude and Latency}

ERPs elicited at Fz by the standard and each deviant are illustrated in Figure 1 for musician and nonmusician children.

Results of the ANOVAs are reported in Table 2 and results of post hoc Tukey tests are included in text.

MMN amplitude was larger and MMN latency was shorter to VOT deviants (amplitude: $-2.65 \mu \mathrm{V}$, latency: $111 \mathrm{msec}$ ) than to frequency deviants (amplitude: $0.13 \mu \mathrm{V}, p<.001$; latency: 300 msec, $p<.001$ ) and to duration deviants (amplitude: $-1.02 \mu \mathrm{V}, p<.002$; latency: $351 \mathrm{msec}, p<.001$; main effect of dimension on both MMN amplitude and latency). MMN latency was also shorter for large (236 msec) than for small deviants (272 msec; main effect of deviance size). Moreover, MMNs were larger over fronto-central (frontal: $-1.22 \mu \mathrm{V}$, central: $-1.32 \mu \mathrm{V}$ ) than parietal regions $(-0.70 \mu \mathrm{V}$; main effect of the antero-posterior factor).

Finally, the main effect of Group was not significant $(p=$ $.35)$, but the Group $\times$ Dimension interaction was significant on MMN amplitude. ${ }^{4}$ To further examine this interaction, separate ANOVAs were conducted for each deviant.

For frequency deviants, results showed no main effect of Group $($ musician $=-0.1 \mu \mathrm{V}$, nonmusician $=0.35 \mu \mathrm{V}, p=$ .30). The Group $\times$ Deviance size $\times$ Laterality interaction was significant, but results of post hoc Tukey tests revealed no significant between-group differences (see Figure 2).

For duration deviants, MMNs were larger in musicians $(-1.53 \mu \mathrm{V})$ than in nonmusicians $(-0.51 \mu \mathrm{V}$; main effect of Group) with largest differences for large deviants over the left hemisphere and at midline electrodes (Group $\times$ Deviance size $\times$ Laterality interaction, see Figure 3 ).

For VOT deviants and in musician children only, large deviants $(-2.24 \mu \mathrm{V})$ elicited larger MMNs than small deviants $(-1.43 \mu \mathrm{V}, p=.05)$. No differences were found between large and small deviants for nonmusicians (small deviants: $-2.77 \mu \mathrm{V}$, large deviants: $-2.82 \mu \mathrm{V}, p=.99$; Group $\times$ Deviance size interaction). Between-group differences were larger at midline electrodes than over the 
Figure 1. ERPs at Fz electrode to standard (solid line), large deviants (dashed line), and small deviants (dotted line) in frequency, duration, and VOT for musician and nonmusician children.

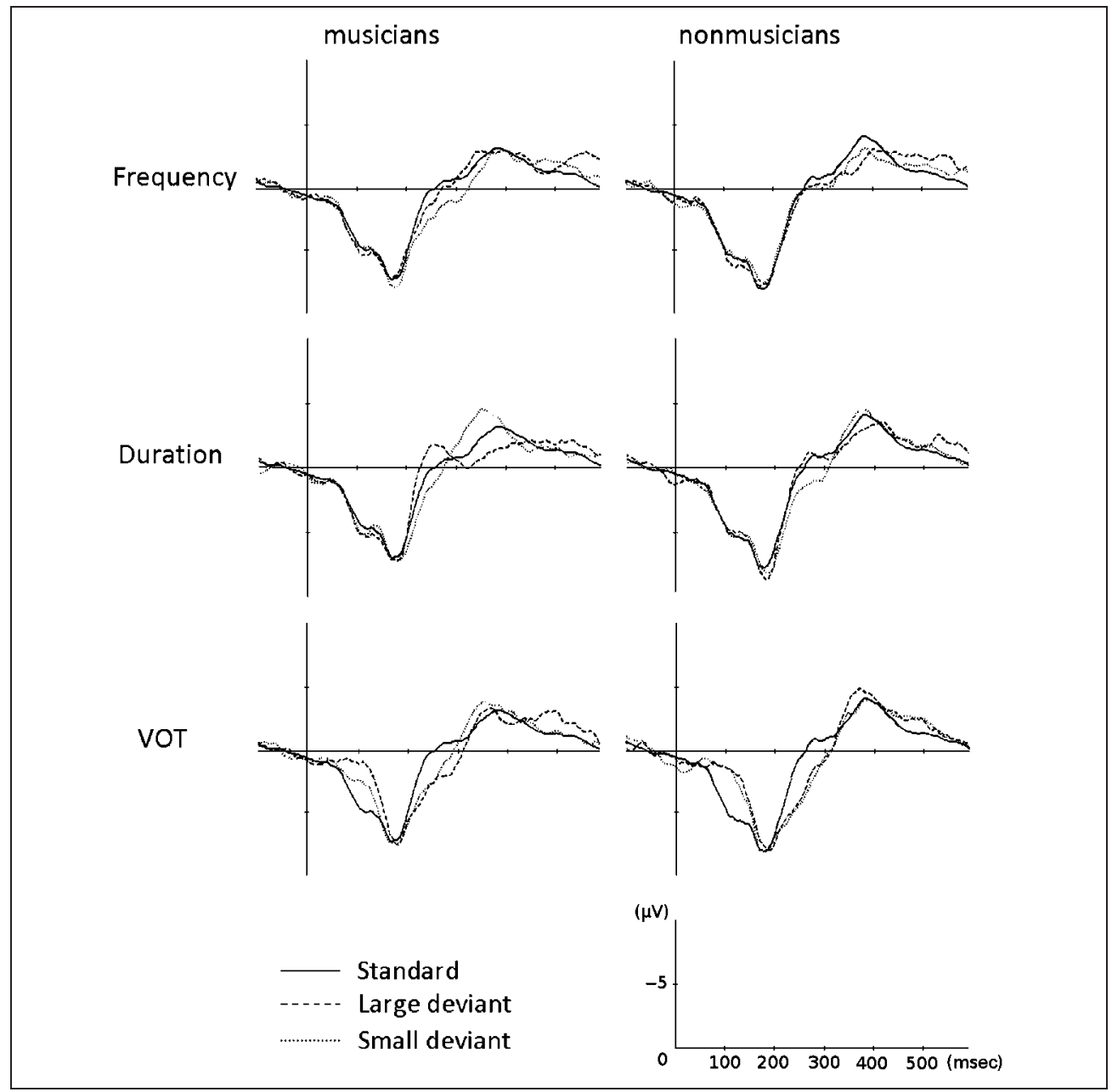

left and right hemispheres (Group $\times$ Laterality interaction; see Figure 4).

\section{P3a Amplitude}

Results also showed larger P3a components to VOT $(1.87 \mu \mathrm{V})$ than to frequency $(0.05 \mu \mathrm{V}, p<.001)$ and to duration deviants $(0.46 \mu \mathrm{V}, p<.001$; main effect of dimension: $F(2,52)=$ $11.9, p<.001)$. Moreover, P3a components were larger over fronto-central (frontal: $1.31 \mu \mathrm{V}$, central: $1.15 \mu \mathrm{V}$ ) than over parietal regions $(0.41 \mu \mathrm{V}, p<.001$; main effect of anteroposterior: $F(2,52)=30.33, p=<.001)$. Neither the main effect of group $(p=.59)$ nor the Group $\times$ Dimension interaction $(p>.48)$ were significant.

\section{Active Discrimination}

Results of the ANOVAs are reported in Table 3 and are illustrated in Figure 5.

\section{Percentage of Errors}

The error rate was lower for musician (26\% [SD = 16\%]) than for nonmusician children $(39 \%$ [SD $=18 \%]$; main effect of Group) but only for the frequency and duration deviants (musicians: frequency $=20 \%[S D=15 \%]$ and duration $=21 \%[S D=12 \%]$; nonmusicians: frequency $=$ $40 \%[S D=17 \%]$ and duration $=37 \%[S D=16 \%])$. No between-group differences were found for the VOT deviants (musicians $=37 \%$ [SD $=20 \%]$; nonmusicians $=40 \%$ $[S D=22 \%]$; Group $\times$ Dimension interaction). Moreover, for all deviants, the error rate was always lower for large than for small deviants (frequency $=19 \%$ vs. $41 \%$ [SD $=16 \%$ vs. $22 \%]$, duration $=10 \%$ vs. $47 \%$ [SD $=11 \%$ vs. $22 \%]$, vOT $=$ $30 \%$ vs. $51 \%$ [SD $=25 \%$ vs. $21 \%$ ]; main effects of Deviance Size). Finally, participants made less errors to frequency $(29 \%[S D=18 \%])$ and duration $(28 \%$ [SD = 15\%]) deviants than to VOT deviants ( $40 \%$ [SD $=20 \%]$; main effect of Dimension).

\section{RTs}

RTs were shorter for musician (716 $\mathrm{msec}[S D=88 \mathrm{msec}]$ ) than for nonmusician children (786 msec [SD = $111 \mathrm{msec}]$; main effect of group). The Group $\times$ Dimension interaction was not significant in the main ANOVA but as found for the error rate, results of separate ANOVAs showed that betweengroup differences were only found for the frequency and 
duration deviants (musicians: frequency $=723 \mathrm{msec}[S D=$ $77 \mathrm{msec}]$ and duration $=695 \mathrm{msec}[S D=82 \mathrm{msec}]$; nonmusicians: frequency $=798 \mathrm{msec}[S D=101 \mathrm{msec}]$ and duration $=779 \mathrm{msec}[S D=122 \mathrm{msec}])$. No betweengroup differences were found for VOT deviants (musicians: $730 \mathrm{msec}$ [ $S D=104 \mathrm{msec}$; nonmusicians: $780 \mathrm{msec}$ [ $S D=$ $110 \mathrm{msec}]$ ). Moreover, RTs were shorter for large (690 msec $[S D=115 \mathrm{msec}])$ than for small deviants (811 $\mathrm{msec}[S D=$ $131 \mathrm{msec}]$; main effect of Deviance size). This deviance size effect was larger for frequency and duration deviants (large vs. small deviants for frequency $=707 \mathrm{msec}$ vs. $813 \mathrm{msec}$ $[S D=97 \mathrm{msec}$ vs. $128 \mathrm{msec}]$ and for duration $=645 \mathrm{msec}$ vs. $828 \mathrm{msec}[S D=112 \mathrm{msec}$ vs. $127 \mathrm{msec}]$ ) than for VOT deviants (718 msec vs. $792 \mathrm{msec}[S D=136 \mathrm{msec}$ vs. $136 \mathrm{msec}$; Dimension $\times$ Deviance size interaction). For VOT deviants, musicians were faster for large $(663 \mathrm{msec}$ $[S D=102 \mathrm{msec}])$ than for small deviants (798 msec $[S D=$ $133 \mathrm{msec}$; $p$ <.01) but no Deviance size effect was found for nonmusicians (large $=773 \mathrm{msec}[S D=136 \mathrm{msec}]$ and small $=787 \mathrm{msec}[S D=136 \mathrm{msec}] ; p>.98$; Group $\times$ Deviance size interaction).

\section{DISCUSSION}

This study aimed at testing the hypothesis of a positive influence of musical expertise on the passive and active processing of speech sounds in 9-year-old children. In line with this hypothesis, results clearly showed significant differences between musician and nonmusician children. During passive listening, duration and VOT deviants were processed differently by the two groups, with no differences for frequency deviants. By contrast, during active listening, between-group differences were found for all three dimensions. Importantly, and in line with previous results from both adults (Pakarinen et al., 2009) and children (Lovio et al., 2009), large MMNs to duration and VOT deviants were elicited using the multifeature paradigm with speech sounds. The MMNs showed the typical polarity inversion at mastoids electrodes (using the nose reference) as well as the typical fronto-central distribution (Näätänen et al., 2007). Moreover, MMN latency and RTs were shorter and the error rate was lower to large than to small deviants independently of the types of deviants. In

Table 2. Summary of Statistical Analyses on MMN Amplitude and Latency (Between-group ANOVA)

\begin{tabular}{|c|c|c|c|c|c|c|}
\hline \multirow[b]{3}{*}{ Effect } & \multicolumn{6}{|c|}{ ANOVAs } \\
\hline & \multicolumn{3}{|c|}{ Amplitude } & \multicolumn{3}{|c|}{ Latency } \\
\hline & $d f$ & $F$ & $p$ & $d f$ & $F$ & $p$ \\
\hline \multicolumn{7}{|l|}{ Main ANOVA (All Deviants) } \\
\hline Group & $(1,26)$ & $<1$ & & $(1,26)$ & $<1$ & \\
\hline Dimension & $(2,52)$ & 29.72 & .001 & $(2,52)$ & 29.72 & .001 \\
\hline Deviance size & $(1,26)$ & $<1$ & & $(1,26)$ & 86.15 & .001 \\
\hline Anterior-Posterior Factor & $(2,52)$ & 11.4 & .001 & & & \\
\hline Group $\times$ Dimension & $(2,52)$ & 3.74 & .03 & $(2,52)$ & 1.99 & .15 \\
\hline \multicolumn{7}{|l|}{ Separate ANOVAs by Dimension } \\
\hline \multicolumn{7}{|l|}{ Frequency } \\
\hline Group & $(1,26)$ & 1.11 & .30 & \multirow[t]{2}{*}{$(1,26)$} & \multirow[t]{2}{*}{$<1$} & \\
\hline Group $\times$ Deviance size $\times$ Laterality & $(2,52)$ & 4.33 & .03 & & & \\
\hline \multicolumn{7}{|l|}{ Duration } \\
\hline Group & $(1,26)$ & 5.06 & .03 & $(1,26)$ & 4.58 & .04 \\
\hline Deviance size & $(1,26)$ & $<1$ & & \multirow[t]{2}{*}{$(1,26)$} & \multirow[t]{2}{*}{145.11} & .001 \\
\hline Group $\times$ Deviance size $\times$ Laterality & $(2,52)$ & 3.71 & .03 & & & \\
\hline \multicolumn{7}{|l|}{ Phonology } \\
\hline Group & $(1,26)$ & 2.04 & .17 & \multirow[t]{2}{*}{$(1,26)$} & \multirow[t]{2}{*}{$<1$} & \\
\hline Group $\times$ Laterality & $(2,52)$ & 3.32 & .04 & & & \\
\hline At Midlines: Group $\times$ Deviance size & $(1,26)$ & 3.65 & .05 & $(1,26)$ & $<1$ & \\
\hline
\end{tabular}

Significant effects and interactions are highlighted in gray. 


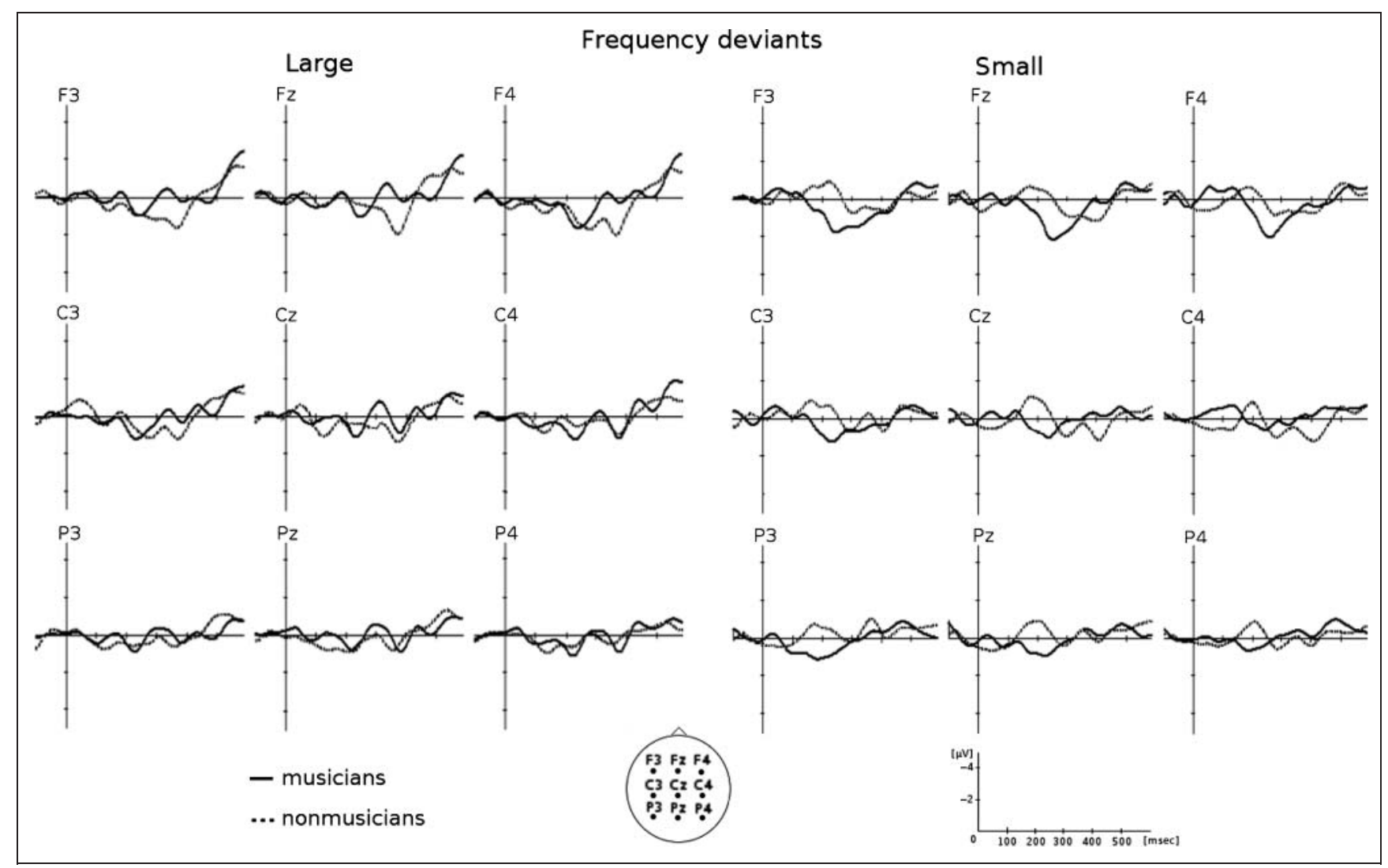

Figure 2. MMNs to large- and to small-frequency deviants for musician (solid line) and nonmusician children (dashed line). Between-group differences were not significant.

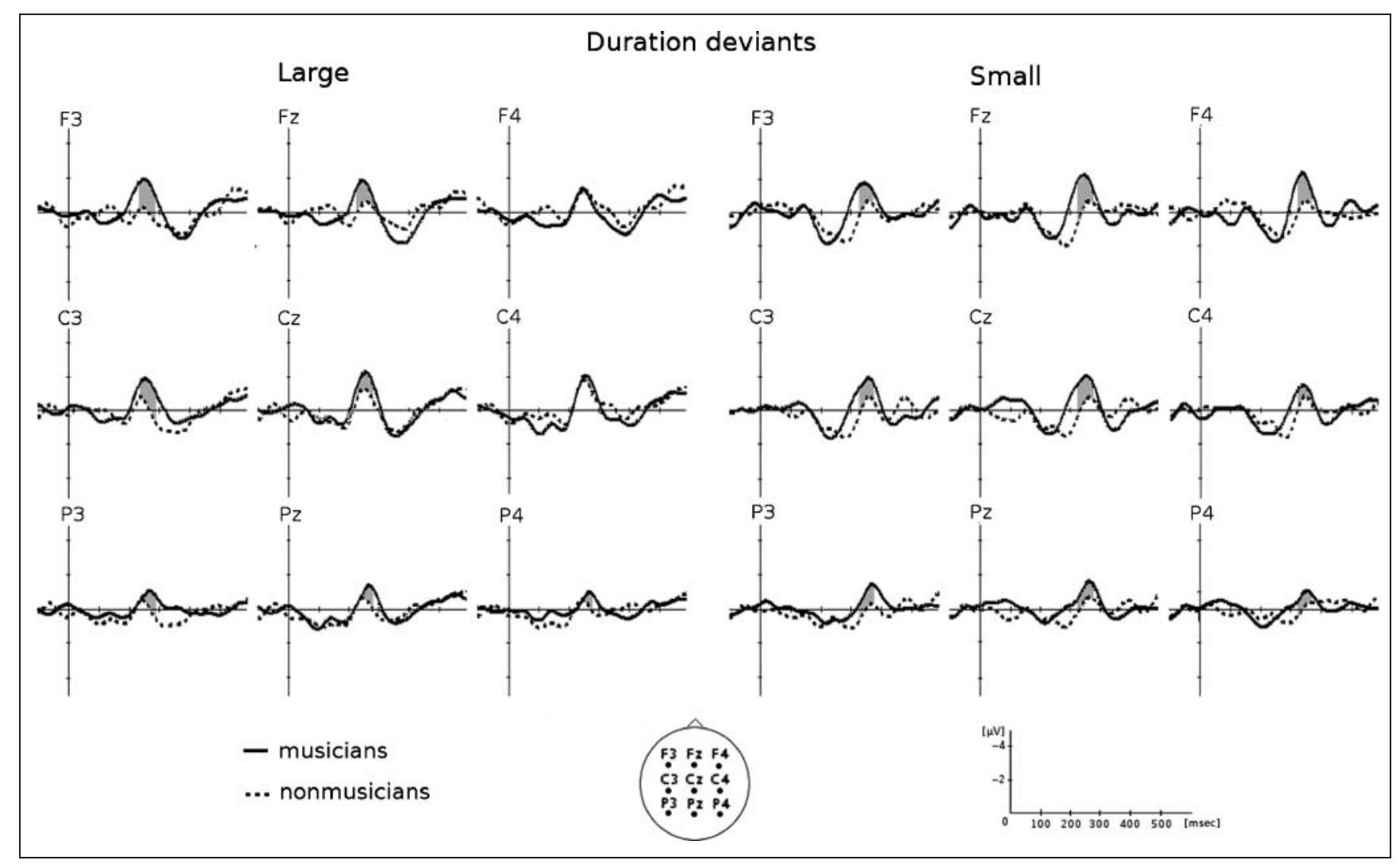

Figure 3. MMNs to large- and to small-duration deviants for musician (solid line) and nonmusician children (dashed line). Gray areas show the latency window within which the between-groups differences were significant. 


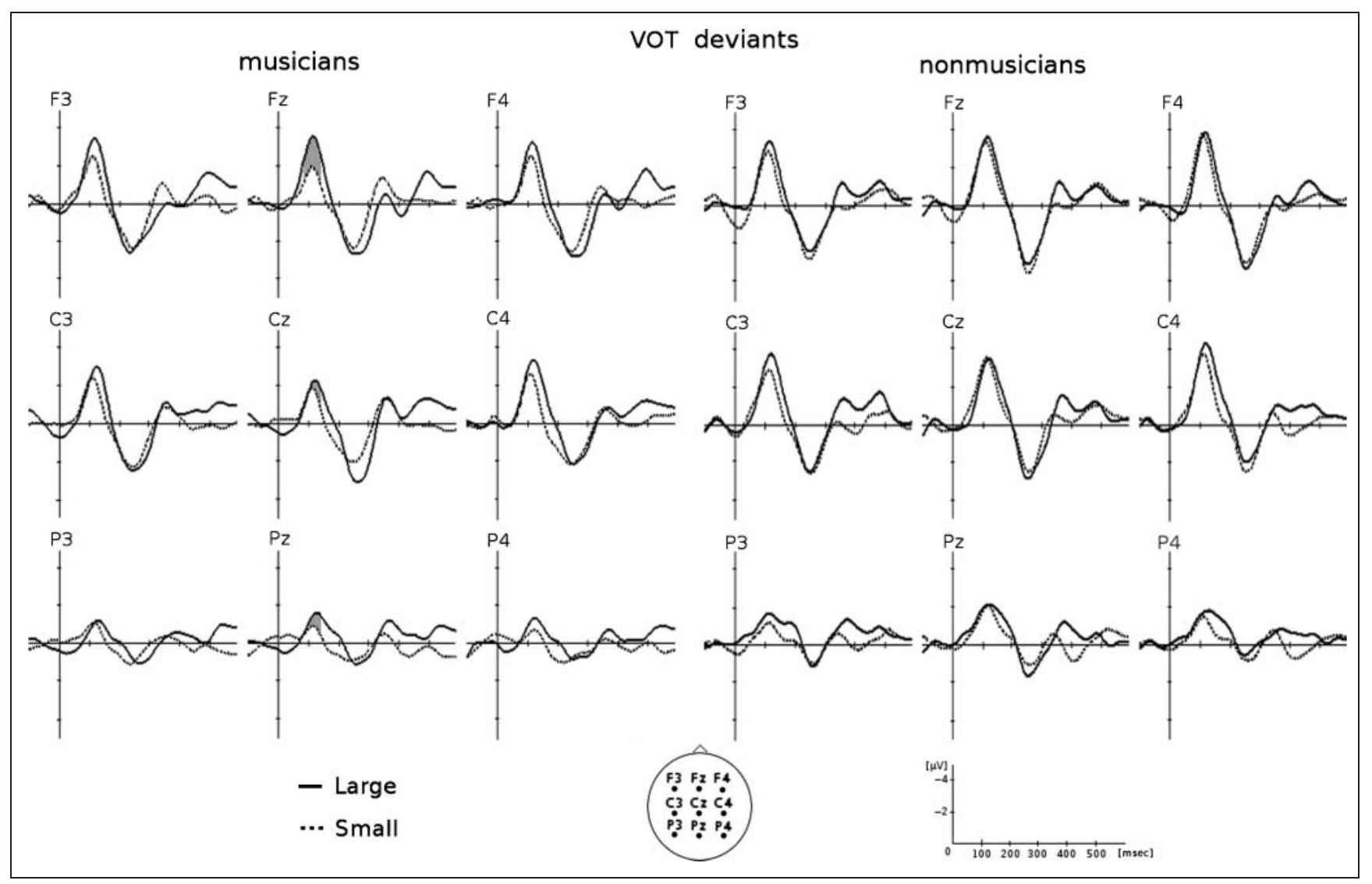

Figure 4. MMNs to VOT deviants for musician and nonmusician children. Overlapped are the MMNs to large (solid line) and to small deviants (dashed line). Gray areas show the latency window within which the deviance size effect was significant.

line with the literature, these results are taken to reflect an overall increase in the difficulty in processing small deviants compared with large deviants (e.g., Novitski et al., 2004; Tiitinen et al., 1994; Sams et al., 1985). Finally, results of $t$ tests aimed at testing the difference between the error rate and chance level (50\%) showed that musician children performed above chance for all deviants except for small VOT deviants. By contrast, nonmusician children performed above chance for all large deviants but were at chance for all small deviants. These findings are discussed below.

Neither large- nor small-frequency deviants elicited clear MMNs in musician and nonmusician children. These results were unexpected in light of the increased sensitivity of musician adults to frequency deviants in harmonic sounds (e.g., Fujioka, Trainor, Ross, Kakigi, \& Pantev, 2004; Brattico et al., 2001; Koelsch et al., 1999). However, as pointed out by Tervaniemi et al. (2009), small-frequency variations may be more relevant to harmonic sounds than to speech sounds because prosodic variations in natural speech are typically larger than the size of musical intervals along the chromatic scale in Western music. Alternatively, the frequency deviants used here were possibly too close to the standard to elicit MMNs (large deviant: $21 \mathrm{~Hz}$ higher than standard, that is $20 \%$ increase; small deviant: $6 \mathrm{~Hz}$ higher than standard, that is $6 \%$ increase). Moreover, because all deviants were intermixed within the sound sequence, it is possible that the frequency deviants were also less salient than duration and VOT deviants. In line with this interpretation, results of the general ANOVAs revealed that MMN amplitude was larger to VOT deviants, intermediate to duration deviants and smallest to frequency deviants. Finally, and as can be seen from Figure 2, MMNs to frequency deviants were possibly masked by larger and earlier P3a components in musicians than in nonmusicians.

In the active listening condition, frequency discrimination performance was higher (lower error rate and faster RTs) for musician than for nonmusician children for both large- and small-frequency deviants. Importantly, these results at the syllable level extend previous findings showing improved active discrimination of pitch manipulations at the word level in musician compared with nonmusician children (Magne et al., 2006) and in nonmusician children trained with music (Moreno et al., 2009).

In summary, results for frequency deviants revealed a dissociation between the passive (MMN) and active (discrimination task) listening conditions. Similar contrasts have already been reported in the literature (e.g., Tervaniemi et al., 2005, 2009; Pakarinen, Takegata, Rinne, Huotilainen, \& Näätänen, 2007). For instance, Tervaniemi et al. (2005) found enhanced discrimination accuracy for pitch deviants in nonspeech sounds in musicians compared with nonmusicians with no between-group differences in MMN amplitude. This was taken as evidence that the memory trace established during passive listening (that always preceded 
Table 3. Summary of Statistical Analyses on Percentage of Errors and RTs in the Active Discrimination Task (Between-group ANOVA)

\begin{tabular}{llll}
\hline & \multicolumn{3}{c}{ ANOVAS } \\
\cline { 2 - 4 } Effect & $d f$ & $F$ & $p$ \\
\hline
\end{tabular}

Percentage of Errors

Main ANOVA (all deviants)

$\begin{array}{lcrc}\text { Group } & (1,26) & 5,22 & .03 \\ \text { Deviance size } & (1,26) & 216,58 & .001 \\ \text { Dimension } & (2,52) & 7,57 & .001 \\ \text { Group } \times \text { Dimension } & (2,52) & 3,15 & .05 \\ \text { Dimension } \times \text { Deviance size } & (2,52) & 7,09 & .002\end{array}$

Separate ANOVAs by dimension

Frequency

\begin{tabular}{llll} 
Group & $(1,26)$ & 9,77 & .004 \\
Deviance size & $(1,26)$ & 53,77 & .001 \\
Group $\times$ Deviance size & $(1,26)$ & $<1$ & \\
Duration & & & \\
Group & $(1,26)$ & 9,06 & .005 \\
Deviance size & $(1,26)$ & 135.67 & .001 \\
Group $\times$ Deviance size & $(1,26)$ & $<1$ & \\
Phonology & & & \\
Group & $(1,26)$ & $<1$ & \\
Deviance size & $(1,26)$ & 36,86 & .001 \\
\hline Group $\times$ Deviance size & $(1,26)$ & $<1$ & \\
\end{tabular}

$R T$

Main ANOVA (all deviants)

\begin{tabular}{lccc} 
Group & $(1,26)$ & 54,32 & .05 \\
Deviance size & $(1,26)$ & 98,36 & .0001 \\
\hline Dimension & $(2,52)$ & 1,41 & .25 \\
Group $\times$ Dimension & $(2,52)$ & $<1$ & \\
Dimension $\times$ Deviance size & $(2,52)$ & 5,69 & .005
\end{tabular}

Separate ANOVAs by dimension

Frequency

\begin{tabular}{lccc} 
Group & $(1,26)$ & 4,38 & .04 \\
Deviance size & $(1,26)$ & 30,46 & .001 \\
Group $\times$ Deviance size & $(1,26)$ & $<1$ & \\
Duration & & & \\
Group & $(1,26)$ & 4,96 & .03 \\
Deviance size & $(1,26)$ & 76,41 & .001 \\
Group $\times$ Deviance size & $(1,26)$ & $<1$ & \\
\hline
\end{tabular}

Table 3. (continued)

\begin{tabular}{lccc}
\hline \multirow{2}{*}{ Effect } & \multicolumn{3}{c}{ ANOVAs } \\
\cline { 2 - 4 } Phonology & $d f$ & $F$ & $p$ \\
Group & & & \\
Deviance size & $(1,26)$ & $<1$ & \\
Group $\times$ Deviance size & $(1,26)$ & 7,41 & .01 \\
\hline
\end{tabular}

Significant effects and interactions are highlighted in gray.

active listening) was later used more efficiently in the active discrimination task by musicians than by nonmusicians. Alternatively, because the frequency deviants were possibly less salient or smaller in their relative deviance size than the other deviants in our experiment (see above), it is possible that focusing attention on the sequence of syllables was mandatory for discriminating the frequency deviants from the standards.

By contrasts, for both large- and small-duration deviants, MMN amplitude was larger for musician than for nonmusician children. Thus, in line with our hypothesis and with the results of Milovanov et al. (2009), who tested children with high musical aptitudes, our results reflect enhanced preattentive processing of the duration of speech sounds in musician compared with nonmusician children. Moreover, in musicians, the MMN to large-duration deviants was larger over the left hemisphere and midline electrodes than over the right hemisphere. Such a scalp distribution is in line with results showing greater involvement of the left hemisphere in duration processing (Poeppel, 2001; Mills \& Rollman, 1979) and with the left lateralization of rhythmic processing in adult musicians (e.g., Vuust et al., 2005).

The advantage for processing duration among musician children was also found in the active listening condition: discrimination of duration deviants was more accurate and faster in musician than in nonmusician children. These results, thus, extend those reported by Marie, Magne, et al. (2011), showing that adult musicians are more sensitive to subtle changes in the metric structure of words than nonmusicians. By showing a positive influence of musical expertise on the passive and active processing of duration in speech sounds, these results with children argue in favor of common processing of duration in music and speech.

Results are somewhat more complex for VOT deviants. The deviance size effect (i.e., larger MMN to large than to small deviants) was only significant in musicians. In nonmusician children, the MMNs to large and small deviants were not significantly different from each other, and both were similar in amplitude to the MMN elicited by large deviants in musicians (see Figure 4). Strikingly similar results were found on RTs: The deviance size effect was significant in musicians, with faster RTs to large than to small deviants, but not in nonmusicians. Moreover, as found for MMN amplitude, RTs to large and small deviants in nonmusicians 
were not significantly different and both were similar to RTs to large deviants in musicians (see Figure 5). As mentioned above (Sharma \& Dorman, 1999; Dehaene-Lambertz \& Baillet, 1998; Dehaene-Lambertz, 1997), within-phonemic category deviants typically elicit small (or no) MMNs, whereas across-phonemic category deviants elicit large MMNs. Thus, it may be that large deviants "Ba -8 msec" that are very close to "Pa" on the continuum were processed as across-category changes by musician as well as by nonmusician children, thereby producing large MMNs and fast RTs in both groups. Importantly, small deviants also seemed to be perceived as across-phonemic category changes by nonmusician children because results showed similar MMN amplitude and RTs to small and to large deviants. Thus, in line with previous results by Phillips et al. (2000) with adults, nonmusician children seem to passively process all changes (whether large or small) as across-phonemic category changes. By contrast, musician children seemed to hear the subtle difference between small and large deviants (smaller MMN amplitude and slower RTs to small than to large deviants). Therefore, musical training, by refining the network of brain structures responsible for processing the acoustic features of sounds, seems to increase musicians' sensitivity to changes in voicing duration. On this account, enhanced acoustic processing of duration in musician children allows them to establish finer representations of VOT which, in turn, help them develop more appropriate phonological representations (see Phillips et al., 2000, for similar logic).

To summarize, musical expertise was shown to facilitate the passive and the active processing of VOT deviants. This finding is consistent with previous results showing that musical skills are reliably related to phonological awareness in adults and children (e.g., Moreno et al., 2009; Slevc \& Miyake, 2006; Overy et al., 2003; Anvari et al., 2002). Moreover, results of a recent study by Jones, Lucker, Zalewski, Brewer, and Drayna (2009) showed that musical pitch recognition deficits were associated with phonological deficits in the processing of speech sounds, thereby highlighting the link between the two domains. Although these studies aimed at testing active listening, our results also showed enhanced processing of VOT deviants in musicians during passive listening.

Before concluding, we wish to comment on two interesting observations. First, the absence of a main effect of Group in the general ANOVA on MMN amplitude and latency as well as on P3 amplitude showed that musicians were not more likely to show larger or earlier ERP components than nonmusician children. Consequently, general differences between the two groups are not likely to explain the present findings. Second, VOT deviants elicited a larger P3a than frequency and duration deviants. The P3a is typically considered as an index of involuntary and automatic orientating of attention (Escera, Alho, Winkler, \& Näätänen, 1998; Knight, 1996; Courchesne, Hillyard, \& Galambos, 1975; Squires, Squires, \& Hillyard, 1975) toward novel and surprising stimuli (for a review, see Näätänen et al., 2007). Thus, VOT deviants seemed to automatically attract children's attention more than the other deviants. This may not be surprising given that, in French, phonological variations are important at the segmental level as they can change the meaning of words. Moreover, as mentioned
Figure 5. Percentage of errors and RTs (in msec) to the duration, frequency, and VOT deviants in the discrimination task for musician (white) and nonmusician children (gray). Results are averaged across large and small deviants. The errors bars represent standard deviation, and the asterisks indicate significant differences $\left({ }^{*} p<.05, * * * p<.001\right)$

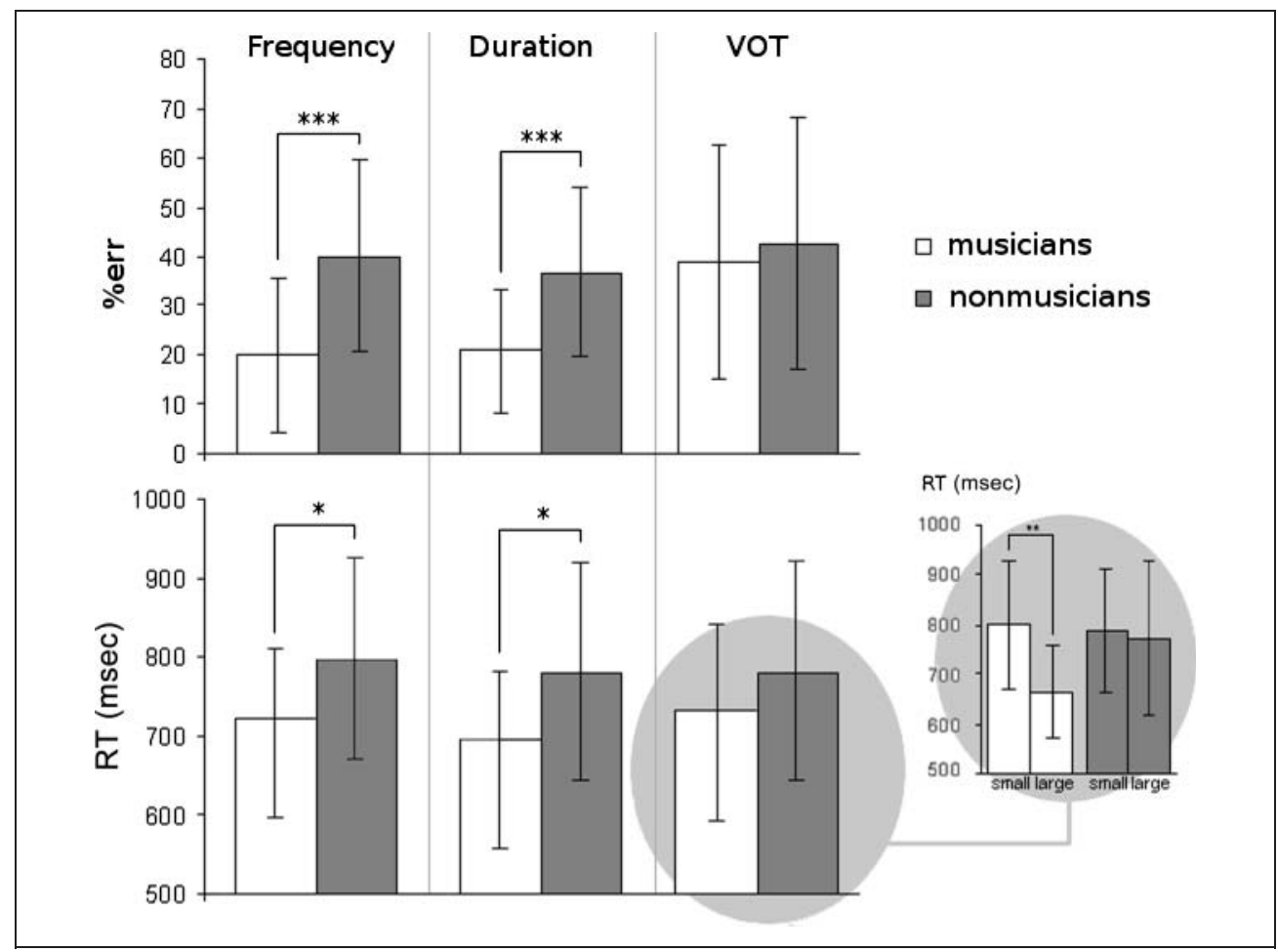


above, VOT deviants also elicited larger MMNs with a shorter latency than both frequency and duration deviants. Because MMN amplitude increases and latency decreases with the perceived magnitude of the deviance (e.g., Pakarinen et al., 2007; Novitski et al., 2004; Tiitinen et al., 1994; Sams et al., 1985), these results support the interpretation that VOT deviants were preattentively perceived as more salient than the other deviants. However, another explanation can account for differences in MMN latency. For VOT deviants, the acoustic variation occurred right at stimulus onset $(0 \mathrm{msec})$ whereas such changes occurred later for both the frequency and duration deviants (i.e., on the vowel at 91 msec after stimulus onset), thereby possibly influencing between-deviant differences in MMN latency.

\section{Conclusion}

The present results clearly showed enhanced passive and active processing of the acoustic and phonological properties of syllables, the basic units of speech, in musician compared with nonmusician children. These results are theoretically important for two reasons. First, if the language system was modular and therefore "informationally encapsulated" (Fodor, 1983, 2000), there would be no reason for musical expertise to influence language processing. By showing that musical training in children influences the perception of syllables and by taking into account previous results with adults and children showing that musical expertise influences the active processing of pitch in words (Marie, Delogu, Lampis, Olivetti Belardinelli, \& Besson, 2011; Magne et al., 2006; Schön et al., 2004) and of duration in speech sounds (Marie, Magne, et al., 2011; Musacchia et al., 2007) as well as the automatic encoding of pitch contour in speech (Bidelman et al., 2011; Chandrasekaran \& Kraus, 2010; Musacchia et al., 2007; Wong et al., 2007), these results argue against the idea that the language system is modular. Second, our findings indicate that musical training not only facilitates the processing of acoustic parameters such as frequency and duration but also improves the perception of changes in VOT, a more abstract linguistic parameter important for the development of phonological representations. Insofar as phonological representations are specific to language, these results demonstrate positive transfer of training effects from musical expertise to speech processing.

Pragmatically, these results provide new evidence for the importance of music lessons at school and open new perspectives to facilitate the development of the phonological representations necessary for fluent reading. By improving the discrimination of frequency and duration in speech sound, musical training may help children with dyslexia develop more robust phonological representations and thereby enhance their reading ability. Moreover, if strong links do exist between the acoustic and the more abstract levels of language processing, such as between frequency, duration, and VOT, musical training may also enhance children's abilities to learn foreign languages, particularly in the case of those languages in which pitch and duration variations are linguistically relevant, as is true of tone (e.g., Mandarin Chinese, Thaï, and many African languages) and quantity languages (e.g., Finnish and Japanese).

\section{Acknowledgments}

This research was conducted at the Institut de Neurosciences Cognitives de la Méditerranée (INCM), CNRS \& Université de la Méditerranée, Marseille, France, and was supported by a grant from the ANR-Neuro (024-01) to Mireille Besson. Julie Chobert and Clément François are Ph.D. students also supported by the ANR-Neuro (024-01). We thank Noël Nguyen for helping us prepare the stimuli, Svetlana Pinet for helping us run part of the experiment, and Nia Cason and Deidre Bolger for their attentive reading of the manuscript. We also thank all the children who participated in this study and their parents.

Reprint requests should be sent to Julie Chobert, Language Music and Motricity Team, INCM-CNRS, 31 chemin Joseph Aiguier, 13402 Marseille Cedex 20, France, or via e-mail: chobert@ incm.cnrs-mrs.fr.

\section{Notes}

1. The main advantage of this design compared with the classical MMN design (oddball) is that several deviants can be tested within the same auditory sequence, thereby maintaining the duration of the experiment at a reasonable length.

2. The VOT is a parameter acoustically defined as the interval between noise burst produced at consonant release and the onset of the waveform periodicity associated with vocal cord vibration (Lisker \& Abramson, 1967).

3. We chose the upper limit to be $1200 \mathrm{msec}$ rather than 1000 msec because deviants were always followed by standards to which children made very few errors. Thus, responses occurring within $200 \mathrm{msec}$ from standard onset were more likely to be delayed responses to the preceding deviants than very fast wrong responses to standards.

4. The Group $\times$ Dimension interaction was not significant on MMN latency, but we computed separate ANOVAs to determine whether similar results were found for each dimension. Only results for the duration dimension revealed a significant main effect of Group with shorter latency for musicians (291 msec) than for nonmusicians (308 msec; main effect of Deviance Size, see Table 2)

5. Following Fodor $(1983,2000)$, this implies that that the computations necessary to process language unfold independently of other types of knowledge (see Besson \& Schön, in press; Fedorenko, Patel, Casasanto, Winawer, \& Gibson, 2009, for further discussion)

\section{REFERENCES}

Anvari, S. H., Trainor, L. J., Woodside, J., \& Levy, B. A. (2002). Relation among musical skills, phonological processing and early reading ability in preschool children. Journal of Experimental Psychology, 83, 111-130.

Besson, M., \& Faita, F. (1995). An event related potential (ERP) study of musical expectancy: Comparison of musicians with nonmusicians. Journal of Experimental Psychology: Human Perception and Performance, 21, 1278-1296.

Besson, M., \& Schön, D. (in press). What remains of modularity? In P. Rebuschat, M. Rohrmeier, J. Hawkins, \& I. Cross (Eds.), Language and music as cognitive systems. Oxford: Oxford University Press. 
Bidelman, G. M., Gandour, J. T., \& Krishnan, A. (2011). Cross-domain effects of music and language experience on the representation of pitch in the human auditory brainstem. Journal of Cognitive Neuroscience, 23, 425-434.

Boersma, P., \& Weenink, D. (2001). Praat (version 4.0) [Computer software]. Retrieved from www.praat.org, July 4, 2011.

Brattico, E., Näätänen, R., \& Tervaniemi, M. (2001). Context effects on pitch perception in musicians and nonmusicians: Evidence from event-related potential recordings. Music Perception, 19, 199-222.

Chandrasekaran, B., \& Kraus, N. (2010). The scalp-recorded brainstem response to speech: Neural origins. Psychophysiology, 47, 236-246.

Chandrasekaran, B., Krishnan, A., \& Gandour, J. T. (2009). Relative influence of musical and linguistic experience on early cortical processing of pitch contours. Brain and Language, 108, 1-9.

Courchesne, E., Hillyard, S. A., \& Galambos, R. (1975). Stimulus novelty, task relevance and the visual evoked potential in man. Electroencephalography and Clinical Neurophysiology, 39, 131-143.

Dehaene-Lambertz, G. (1997). Electrophysiological correlates of categorical phoneme perception in adults. NeuroReport, 8, 919-924.

Dehaene-Lambertz, G., \& Baillet, S. (1998). A phonological representation in the infant brain. NeuroReport, 9, 1885-1888.

Escera, C., Alho, K., Winkler, I., \& Näätänen, R. (1998). Neural mechanisms of involuntary attention to acoustic novelty and change. Journal of Cognitive Neuroscience, 10, 590-604.

Fedorenko, E., Patel, A., Casasanto, D., Winawer, J., \& Gibson, E. (2009). Structural integration in language and music: Evidence for a shared system. Memory \& Cognition, 37, 1-9.

Fodor, J. A. (1983). The modularity of mind. Cambridge, MA: MIT Press.

Fodor, J. A. (2000). The mind doesn't work that way. Cambridge, MA: MIT Press

Fujioka, T., Trainor, L. J., Ross, B., Kakigi, R., \& Pantev, C. (2004). Musical training enhances automatic encoding of melodic contour and interval structure. Journal of Cognitive Neuroscience, 16, 1010-1021.

Gaser, C., \& Schlaug, G. (2003). Brain structures differ between musicians and nonmusicians. The Journal of Neuroscience, 23, 9240-9245.

Hyde, K., Lerch, J., Norton, A., Forgeard, M., Winner, E., Evans, A., et al. (2009). Musical training shapes structural brain development. The Journal of Neuroscience, 29, 3019-3025.

Jasper, H. H. (1958). The ten twenty electrode system of the international federation. Electroencephalography and Clinical Neurophysiology, 10, 371-375.

Jewett, D. L., Romano, M. N., \& Williston, J. S. (1970). Human auditory evoked potentials: Possible brain stem components detected on the scalp. Science, 167, 1517-1518.

Jones, J. L., Lucker, J., Zalewski, C., Brewer, C., \& Drayna, D. (2009). Phonological processing in adults with deficits in musical pitch recognition. Journal of Communication Disorders, 42, 226-234.

Kishon-Rabin, L., Amir, O., Vexler, Y., \& Zaltz, Y. (2001). Pitch discrimination: Are professional musicians better than non-musicians? Journal of Basic \& Clinical Physiology $\mathcal{E}$ Pharmacology, 12, 125-143.

Knight, R. T. (1996). Contribution of human hippocampal region to novelty detection. Nature, 383, 256-259.

Koelsch, S., Fritz, T., Schulze, K., Alsop, D., \& Schlaug, G. (2005). Adults and children processing music: An fMRI study. Neuroimage, 25, 1068-1076.
Koelsch, S., Schröger, E., \& Tervaniemi, M. (1999). Superior pre-attentive auditory processing in musicians. NeuroReport, 10, 1309-1313.

Kraus, N., \& Chandrasekaran, B. (2010). Music training for the development of auditory skills. Nature Reviews Neuroscience, 11, 599-605.

Kujala, T., Tervaniemi, M., \& Schröger, E. (2007). The mismatch negativity in cognitive and clinical neuroscience: Theoretical and methodological considerations. Biological Psychology, 74, 1-19.

Lisker, L., \& Abramson, A. S. (1967). Some effects of context on voice onset time in English stops. Language and Speech, 10, $1-28$.

Loui, P., Alsop, D., \& Schlaug, G. (2009). Tone-deafness: A disconnection syndrome? Journal of Neuroscience, 29, 10215-10220.

Lovio, R., Pakarinen, S., Huotilainen, M., Alku, P., Silvennoinen, S., Näätänen, R., et al. (2009). Auditory discrimination profiles of speech sound changes in 6-year-old children as determined with the multi-feature MMN paradigm. Clinical Neurophysiology, 120, 916-921.

Magne, C., Schön, D., \& Besson, M. (2006). Musician children detect pitch violations in both music and language better than non-musician children. Journal of Cognitive Neuroscience, 18, 199-211.

Marie, C., Delogu, F., Lampis, G., Olivetti Belardinelli, M., \& Besson, M. (2011). Influence of musical expertise on segmental and tonal processing in Mandarin Chinese. Journal of Cognitive Neuroscience, 23, 2701-2715.

Marie, C., Kujala, T., \& Besson, M. (in press). Musical and linguistic expertise influence pre-attentive and attentive processing of non-speech sounds. Cortex. (doi: 10.1016/j.cortex.2010.11.006)

Marie, C., Magne, C., \& Besson, M. (2011). Musicians and the metric structure of words. Journal of Cognitive Neuroscience, 23, 294-305.

Marques, C., Moreno, S., Castro, S. L., \& Besson, M. (2007). Musicians detect pitch violation in a foreign language better than non-musicians: Behavioural and electrophysiological evidence. Journal of Cognitive Neuroscience, 19, 1453-1463.

Mills, L., \& Rollman, G. B. (1979). Left hemisphere selectivity for processing duration in normal subjects. Brain and Language, 7, 320-335.

Milovanov, R., Huotilainen, M., Esquef, P. A. A., Välimäki, V., Alku, P., \& Tervaniemi, M. (2009). The role of musical aptitude and language skills in preattentive duration determination in school-aged children. Neuroscience Letters, 460, 161-165.

Moreno, S., Marques, C., Santos, A., Santos, M., Castro, S. L., \& Besson, M. (2009). Musical training influences linguistic abilities in 8-year-old children: More evidence for brain plasticity. Cerebral Cortex, 19, 712-713.

Musacchia, G., Sams, M., Skoe, E., \& Kraus, N. (2007). Musicians have enhanced subcortical auditory and audiovisual processing of speech and music. Proceedings of the National Academy of Sciences, U.S.A., 104, 15894-15898.

Musacchia, G., Strait, D., \& Kraus, N. (2008). Relationships between behavior, brainstem and cortical encoding of seen and heard speech in musicians and nonmusicians. Hearing Research, 241, 34-42.

Näätänen, R., Gaillard, A. W. K., \& Mäntysalo, S. (1978). Early selective-attention effect on evoked potential reinterpreted. Acta Psychologica, 42, 313-329.

Näätänen, R., Paavilainen, P., Rinne, T., \& Alho, K. (2007). The mismatch negativity (MMN) in basic research of central 
auditory processing: A review. Clinical Neurophysiology, 118, 2544-2590.

Näätänen, R., Pakarinen, S., Rinne, T., \& Takegata, R. (2004). The mismatch negativity (MMN): Towards the optimal paradigm. Clinical Neurophysiology, 115, 140-144.

Näätänen, R., Schröger, E., Karakas, S., Tervaniemi, M., \& Paavilainen, P. (1993). Development of a memory trace for a complex sound in the human brain. NeuroReport, 4, 503-506.

Nikjeh, D. A., Lister, J. J., \& Frisch, S. A. (2009). Preattentive cortical-evoked responses to pure tones, harmonic tones, and speech: Influence of music training. Ear and Hearing, 30, 432-446.

Novitski, N., Tervaniemi, M., Huotilainen, M., \& Näätänen, R. (2004). Frequency discrimination at different frequency levels as indexed by electrophysiological and behavioral measures. Cognitive Brain Research, 20, 26-36.

Overy, K., Nicolson, R. I., Fawcett, A. J., \& Clarke, E. F. (2003). Dyslexia and music: Measuring musical timing skills. Dyslexia, 9, 18-36.

Pakarinen, S., Lovio, R., Huotilainen, M., Alku, P., Näätänen, R., \& Kujala, T. (2009). Fast multi-feature paradigm for recording several mismatch negativities (MMNs) to phonetic and acoustic changes in speech sounds. Biological Psychology, 82, 219-226.

Pakarinen, S., Takegata, R., Rinne, T., Huotilainen, M., \& Näätänen, R. (2007). Measurement of extensive auditory discrimination profiles using the mismatch negativity (MMN) of the auditory event-related potential (ERP). Clinical Neurophysiology, 118, 177-185.

Phillips, C., Pellathy, T., Marantz, A., Yellin, E., Wexler, K., Poeppel, D., et al. (2000). Auditory cortex accesses phonological categories: An MEG mismatch study. Journal of Cognitive Neuroscience, 12, 1038-1055.

Poeppel, D. (2001). Pure word deafness and the bilateral processing of the speech code. Cognitive Science, 25, 679-693.

Reinke, K. S., He, Y., Wang, C., \& Alain, C. (2003). Perceptual learning modulates sensory evoked response during vowel segregation. Brain Research, Cognitive Brain Research, 17, 781-791.

Sams, M., Paavilainen, P., Alho, K., \& Näätänen, R. (1985). Auditory frequency discrimination and event-related potentials. Electroencephalography and Clinical Neurophysiology, 62, 437-438.

Schlaug, G., Norton, A., Overy, K., \& Winner, E. (2005). Effects of music training on brain and cognitive development. Annals of the New York Academy of Sciences, 1060, 219-230.

Schneider, P., Scherg, M., Dosch, H. G., Specht, H. J., Gutschalk, A., \& Rupp, A. (2002). Morphology of Heschl's gyrus reflects enhanced activation in the auditory cortex of musicians. Nature Neuroscience, 5, 688-694.

Schön, D., Magne, C., \& Besson, M. (2004). The music of speech: Electrophysiological study of pitch perception in language and music. Psychophysiology, 41, 341-349.
Schröger, E., \& Wolff, C. (1998). Attentional orienting and reorienting is indicated by human event-related brain potentials. NeuroReport, 26, 3355-3358.

Serniclaes, W. (1987). Etude expérimentale de la perception du trait de voisement des occlusives du français. Ph.D. thesis, l'Université Libre de Bruxelles, Belgium.

Shahin, A., Roberts, L. E., \& Trainor, L. J. (2004). Enhancement of auditory cortical development by musical experience in children. NeuroReport, 15, 1917-1921.

Sharma, A., \& Dorman, M. F. (1999). Cortical auditory evoked potential correlates of categorical perception of voice-onset-time. Journal of the Acoustical Society of America, 106, 1078-1083.

Slevc, L. R., \& Miyake, A. (2006). Individual differences in second language proficiency: Does musical ability matter? Psychological Science, 17, 675-681.

Spiegel, M. F., \& Watson, C. S. (1984). Performance on frequency discrimination tasks by musicians and nonmusicians. Journal of the Acoustical Society of America, 76, 1690-1695.

Squires, N. K., Squires, K. C., \& Hillyard, S. A. (1975). Two varieties of long latency positive waves evoked by impredictable auditory stimuli. Electroencephalography and Clinical Neurophysiology, 38, 387-401.

Tervaniemi, M., Just, V., Koelsch, S., Widmann, A., \& Schröger, E. (2005). Pitch-discrimination accuracy in musicians vs. non-musicians-An event-related potential and behavioral study. Experimental Brain Research, $161,1-10$.

Tervaniemi, M., Kruck, S., De Baene, W., Schröger, E., Alter, K., \& Friederici, A. D. (2009). Top-down modulation of auditory processing: Effects of sound context, musical expertise and attentional focus. European Journal of Neuroscience, 30, 1636-1642.

Tervaniemi, M., Rytkönen, M., Schröger, E., Ilmoniemi, R. J., \& Näätänen, R. (2001). Superior formation of cortical memory traces for melodic patterns in musicians. Learning $\mathcal{E}$ Memory, 8, 295-300.

Tiitinen, H., May, P., Reinikainen, K., \& Näätänen, R. (1994). Attentive novelty detection in humans is governed by pre-attentive sensory memory. Nature, 370, 90-92.

Trainor, L. J., Shahin, A., \& Roberts, L. E. (2003). Effects of musical training on the auditory cortex in children. Annals of the New York Academy of Sciences, 999, 506-513.

Vuust, P., Pallesen, K. J., Bailey, C., van Zuijen, T. L., Gjedde, A., \& Roepstorff, A. (2005). To musicians, the message is in the meter-pre-attentive neuronal responses to incongruent rhythm are left-lateralized in musicians. Neuroimage, 24, 560-564.

Wong, P. C. M., Skoe, E., Russo, N. M., Dees, T., \& Kraus, N. (2007). Musical experience shapes human brainstem encoding of linguistic pitch patterns. Nature Neuroscience, 10, 420-422. 